\title{
Aripiprazole as a Mood Stabiliser in Postpartum Depression With Premorbid Passive-Dependent Personality Structure: a Case Report
}

\author{
Mladen Stajić́, ${ }^{1,2}$, Žana Maksimović ${ }^{1,2}$
}

\section{ABSTRACT}

Depression is becoming a widespread illness. One of the most dangerous types of depression is postpartum depression. In the presented case of postpartum depression, aggravating factor was patient's personality structure. With the frequent giving up on previous therapy, frequent mood swings, and the present feeling of helplessness, the very treatment of depressive episode within the postpartum depression was difficult. In this case report, the introduction of aripiprazole as a drug with a proven effect on mood swings and tendency to mood stabilisation resulted with complete and long-lasting remission.

Key words: postpartum depression, premorbid personality structure, aripiprazole.
(1) Primary Healthcare Centre Modriča, Modriča, the Republic of Srpska, Bosnia and Herzegovina.

(2) PhD Student, Faculty of Medicine, University of Banja Luka, the Republic of Srpska, Bosnia and Herzegovina.

\section{Correspondence:}

MLADEN STAJIĆ

E: mladen_s88@hotmail.com

\section{ARTICLE INFO}

Received: 8 July 2019 Revision received: 30 July 2019 Accepted: 16 Aug 2019

\section{INTRODUCTION}

Postpartum depression is a serious health problem. Studies indicate that the prevalence of postpartum depression in new mothers runs at about $10-15 \%$. Some studies report on a risk as high as $35 \%$. Given the wide spectrum of clinical features and the existence of multiple forms in which this disorder manifests itself, individual studies have shown that a severe depressive episode appears in $7.1 \%$ of mothers postpartum., ${ }^{1,2}$

Clinical studies point out the importance of premorbid personality traits for the development of depressive episodes and/or bipolar disorder. The most important traits of personality are the passive, dependent, and obsessive-compulsive ones dominated by introvertity. ${ }^{3}$

\section{CASE HISTORY}

Patient AC, 28 years old, primipara, had an appointment with a family doctor due to anxiety, sadness, loss of appetite, fear and guilty feeling of "not being a good mother". The problems occurred immediately after discharge from the hospital after delivery. Patient was mainly complaining of reduced social functioning and the inability to fulfil her mother's duties.

During examination the patient had a bent forward posture, looked scruffy, with expressed vascular markings and most of the time was avoiding eye contact. She was cracking knuckles during our conversation and bouncing her legs. The patient had slightly extended latency of response time and tenacity focused on blaming herself for the entire course of pregnancy and peripartum period.

From the medical records and conversation, it was found out about patient's visits to a psychiatrist and a psychologist and about her history of depression. It was also found out about the existence of a passive-dependent personality struc- 
ture, and that the patient had also been treated for a while under the diagnosis of bipolar disorder. After each previous commencement of medication and psychotherapy, the patient would stop using therapy at the first sign of improvement until the next deterioration of her health status. She repeatedly mentioned mood swings: "Several times a week I happen to be either overly happy or sad, for no specific reason. Earlier, these episodes were much less frequent."

The previous therapy included mainly antidepressants like mirtazapine, venlafaxine, sertraline, and lamotrigine as mood stabilisers. However, the patient stated that despite the slight initial improvement, there had never been a drastic improvement in the symptoms while using these medications. "Depressive mood swiftly improves, but sudden mood swings remain, only at a lower intensity." This is stated as the main reason for giving up therapy because "no drug is good enough to cure me". At every attempt to rationalise the problem, the patient would respond: "You are right, but what I can do - I am sick."

During the further diagnostic and therapeutic procedure, after excluding the possibility of harming herself or the child, the patient was sent by her family doctor to see a psychiatrist and a psychologist, to do the basic laboratory tests and to check the hormonal status of the thyroid gland. The family doctor prescribed sertraline $25 \mathrm{mg}$ qd and aripiprazole $2.5 \mathrm{mg}$ qd until seeing the psychiatrist.

Laboratory results and examination of the thyroid gland showed values within the limits of reference interval for age and gender. After examination, the psychiatrist and the psychologist confirmed the initial working diagnosis of postpartum depression with features of a severe depressive episode, and began the pharmacological treatment of acute symptoms, with the aim of introducing her into psychotherapeutic protocols based on the existing passive-dependent personality traits. Aripiprazole and sertraline were confirmed by the psychiatrist as therapy, with daily monitoring of the patient. Over the next 7 days, a gradual improvement in the voluntary-instinctive sphere took place, the patient began to feel better, becoming "happier while being with the child", and thoughts of incom- petence and hopelessness disappeared. Later, the patient, with addition of aripiprazole 2.5 mg qd, was introduced into psychotherapeutic cognitive behavioural treatment (CBT). While adhering to psychopharmacotherapy and regular control and treatment of psychologists and psychiatrists, sudden mood swings disappeared, only the spirit was on a higher level, and the patient began to feel "as a parent ready to give all her love to her child."

\section{DISCUSSION}

In the presented case, the patient suffering from postpartum depression with a feature of major depressive episode, who had a pre-diagnosed passive-dependent personality and a bipolar disorder, is described. It is considered that the structure of the personality contributes to the previous withdrawal from therapy, which implied mainly antidepressants. Numerous studies have demonstrated a high degree of withdrawal from therapy in patients with a personality disorder, ranging from $37.5 \%$ to $58 \% .4,5$

It is believed that in the case of sudden mood swings (within cyclothymia, bipolar disorder, etc), the dominant benefit for the patient comes from using mood stabilisers, while antidepressants are useful in depressive phases. The antidepressants themselves, without mood stabilisers, increase the risk of a manic "switch", and the consequent withdrawal from therapy. ${ }^{6-8}$

The patient in the presented case previously used sertraline, for which she stated that she "believed most" and was a logical choice as an antidepressant in the treatment of the current depressive episode. Having in mind the patient's personality structure and sudden mood swings, it was decided to introduce a mood stabiliser. Aripiprazole has proven to be a good mood stabiliser in numerous studies. A small recommended dose and once-daily administration is one of the features of a drug that was expected to ensure a good patient's compliance. Further, compared to other antipsychotics and mood stabilisers, aripiprazole shows better tolerability and safety profile. 9,10

Aripiprazole is first antipsychotic (followed by quetiapine ER and olanzapine) that according 
to the United States Food and Drug Administration (FDA) received approval for use in addition to antidepressants in the treatment of a severe depressive episode. ${ }^{11-14}$

In this case, it was shown that the combination of antidepressants with aripiprazole led to the withdrawal of the symptoms of depression,

\section{ACKNOWLEDGEMENTS}

None.

\section{REFERENCES}

1. Thurgood S, Avery DM, Williamson L. Postpartum depression (PPD). Am J Clin Med 2009; 6(2):17-22.

2. Beck A, Tatono C. Postpartum depression: it isn't just the blues. Am J Nurs 2006;106(5):40-50.

3. Phillips KA, Gunderson JG, Hirschfeld RMA, Smith LE. A review of depressive personality. Am J Psychiatry 1990;147(7):830-7.

4. Landes SJ, Chalker SA, Comtois KA. Predicting dropout in outpatient dialectical behaviour therapy with patients with borderline personality disorder receiving psychiatric disability. Borderline Personal Disorder Emot Dysregul 2016;3(1):9. doi: 10.1186/s40479-016o043-3.

5. Henzen A, Moeglin C, Giannakopoulos P, Sentissi O. Determinants of dropout in a community-based mental health crisis centre. BMC Psychiatry 2016;16:111. doi: 10.1186/s12888-016-0819-4.

6. Viktorin A, Lichtenstein $\mathrm{P}$, Thase ME, Larsson $\mathrm{H}$, Lundholm C, Magnuson PK, et al. The risk of switch to mania in patients with bipolar disorder during treatment with an antidepressant alone and in combination with a mood stabilizer. Am J Psychiatry 2014;171(10):1063-73.

7. Benvenuti A, Rucci P, Miniati M, Papasogli A, Fagiolini A, Cassano GB, et al. Treatment-emergent mania/hypomania in unipolar patients. Bipolar Disord 2008;10(6):726-32. with long-term persistence and without the occurrence of subsequent sudden mood disorders. Bearing in mind the long history of use of antidepressants and psychotherapy combined, which gave no desired results, it was concluded that adding of aripiprazole as an additional therapy proved to be extremely useful.

\section{CONFLICT OF INTEREST}

None.

8. McIntyre RS, Weiller E. Real-world determinants of adjunctive antipsychotic prescribing for patients with major depressive disorder and inadequate response to antidepressants: a case review study. Adv Ther 2015;32(5):429-44.

9. Muneer A. Aripiprazole in the treatment of refractory mood disorders: a case series. Clin Psychopharmacol Neurosci 2014;12(2):157-9.

10. García-Amador M, Pacchiarotti I, Valentí M, Sanchez RF, Goikolea JM, Vieta E. Role of aripiprazole in treating mood disorders. Expert Rev Neurother 2006 Dec; 6(12):1777-83.

11. Sheng-Min W, Changsu H, Soo-Jung L, Tae-Youn J, Ashwin AP. Second generation antipsychotics in the treatment of major depressive disorder: an update. Chi-Un Pae Chonnam Med J 2016;52(3):159-72.

12. Canadian Agency for Drugs and Technologies in Health. Aripiprazole (Abilify): Depression, Major Depressive Disorder (MDD). Ottawa, ON: Canadian Agency for Drugs and Technologies in Health; 2016 Nov.

13. Cowen PJ. Backing into the future: pharmacological approaches to the management of resistant depression. Psychol Med 2017;47(15):2569-77.

14. Cowen PJ, Anderson IM. New approaches to treating resistant depression. BJPsych Advances 2015;21:31523. 